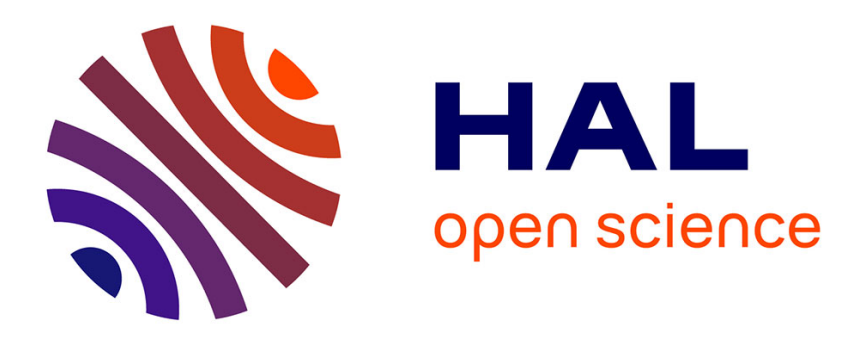

\title{
Would The Right Social Preference Model Please Stand $\mathrm{Up}$ !
}

Dinky Daruvala

\section{To cite this version:}

Dinky Daruvala. Would The Right Social Preference Model Please Stand Up!. Journal of Economic Behavior and Organization, 2009, 73 (2), pp.199. 10.1016/j.jebo.2009.10.003 . hal-00744366

\section{HAL Id: hal-00744366 https://hal.science/hal-00744366}

Submitted on 23 Oct 2012

HAL is a multi-disciplinary open access archive for the deposit and dissemination of scientific research documents, whether they are published or not. The documents may come from teaching and research institutions in France or abroad, or from public or private research centers.
L'archive ouverte pluridisciplinaire HAL, est destinée au dépôt et à la diffusion de documents scientifiques de niveau recherche, publiés ou non, émanant des établissements d'enseignement et de recherche français ou étrangers, des laboratoires publics ou privés. 


\section{Accepted Manuscript}

Title: Would The Right Social Preference Model Please Stand Up!

Author: Dinky Daruvala

PII: $\quad$ S0167-2681(09)00250-9

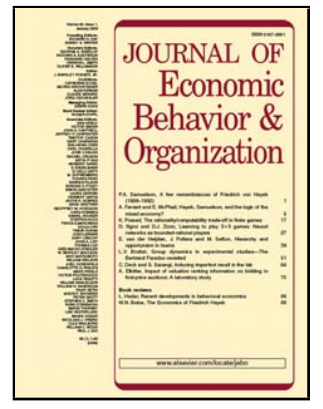

DOI: $\quad$ doi:10.1016/j.jebo.2009.10.003

Reference: $\quad$ JEBO 2458

To appear in: Journal of Economic Behavior \& Organization

Received date: 6-11-2006

Revised date: $\quad 8-10-2009$

Accepted date: $\quad 9-10-2009$

Please cite this article as: Daruvala, D., Would The Right Social Preference Model Please Stand Up!, Journal of Economic Behavior and Organization (2008), doi:10.1016/j.jebo.2009.10.003

This is a PDF file of an unedited manuscript that has been accepted for publication. As a service to our customers we are providing this early version of the manuscript. The manuscript will undergo copyediting, typesetting, and review of the resulting proof before it is published in its final form. Please note that during the production process errors may be discovered which could affect the content, and all legal disclaimers that apply to the journal pertain. 
Submitted title

Would the Right Social Welfare Model Please Stand Up!

Author

Dinky Daruvala Phd

Karlstad University

65188 Karlstad

Sweden.

Tel- work: 0046547001511

Tel Home: 004654566664

e-mail: Dinky.Daruvala@kau.se 


\title{
Would The Right Social Preference Model Please Stand Up!
}

\begin{abstract}
A number of competing social preference models have been developed inspired by the evidence from economic experiments. We test the relative performance of some of these models using an experimental design that is aimed at capturing pure distributional concerns in a multi-person setting. We find that the individuals in this study are heterogeneous, and that they do not follow any single notion of fairness or inequality aversion. In addition, the results suggest that efficiency concerns are not confined to students of economics, but are important to students of all disciplines.
\end{abstract}

Keywords: Difference Aversion, Efficiency, Inequality Aversion, Maximin Criterion, Social Preferences.

JEL Classification: A13, C91, D63.

\section{Introduction}

A number of social preference models have been developed in an effort to explain and organize the evidence from economic experiments. It has been found that people share with others in dictator games, reject offers in ultimatum games, cooperate in public good games, etc., all of which is in direct conflict with traditional microeconomic utility theory.

Fehr and Schmidt (2003) distinguish between two approaches used when explaining the behaviour observed in experiments. The first assumes that some agents have social preferences such that their utility depends not only on their own material payoff, but also on how much the other players receive. The second approach deals with "intention based reciprocity", where it is assumed that the player cares about the intention of her opponent. Although there is much evidence that perceived intentions are often important, this paper focuses solely on the former. Thus, the experiments designed here aim to capture "pure" social preferences, i.e. the nature of distributional concerns rather than strategic or retaliatory preferences. Consequently, this study examines how people respond to unfair outcomes rather than unfair intentions. More specifically, the purpose of this paper is to test the performance of some of the better known social preference theories of difference aversion, maximin preferences and efficiency concerns using real money distributional experiments. 
One category of social preference models are difference aversion models such as those put forward by Loewenstein et al. (1989), Fehr and Schmidt (1999) and Bolton and Ockenfels (2000). These models presume that individuals are averse to differences in relative payoffs and would therefore never sacrifice from their own payoff or reduce the payoff of others if the action resulted in a less equitable outcome. An alternative to the difference aversion models are social welfare models that combine distributional concerns with preferences for efficiency (surplus maximization). The Quasi-maximin model by Charness and Rabin (2000) is one of the more prominent social welfare models where Rawlsian maximin preferences are integrated with efficiency concerns.

The various social preference models provide different explanations for the experimentally observed behaviour, but it is sometimes possible to explain the same experimental data using different models. For example, sharing in dictator games is explained by Andreoni and Miller (2002) as being due to maximin preferences while the same results can be explained by difference aversion according to Bolton and Ockenfels (2000) and Fehr and Schmidt (1999). Similarly, rejections in ultimatum games and cooperation in prisoner's dilemma games is ascribed to difference aversion by Bolton and Ockenfels (2000) and Fehr and Schmidt (1999) while Rabin (1993) interprets such behaviour as reciprocity.

A number of studies have examined and tested various social preference models including those discussed above. The difference aversion models do not incorporate efficiency but there is evidence indicating that efficiency is an important component in preferences. Studies by Charness and Grosskopf (2001), Kritikos and Bolle (2001), Andreoni and Miller (2002), Charness and Rabin (2000, 2002), as well as Engelmann and Strobel (2004) found that a majority of participants are efficiency, rather than equity, orientated. Furthermore, Andreoni and Miller (2002) construe participants who equalize payoffs as exhibiting what Charness and Rabin (2000) describe as social-welfare preferences, rather than difference aversion. Engelmann and Strobel compared the performance of the Bolton-Ockenfels and Fehr-Schmidt models and found a clear 
influence of efficiency and maximin preferences. Overall, they found that the FehrSchmidt model fared better than the Bolton-Ockenfels model, but only when predicting the same choices as the Rawlsian principle. The jury is still out on this issue however. Fehr et al. (2006) found that efficiency was of little concern when they replicated the experiments of Engelmann and Strobel using non-economist respondents. Furthermore, the authors raised doubts regarding the relevance of the Rawlsian motive in strategic games based partly on the experiments by Güth and van Damme (1998), as well as those by Frechette et al. (2003), where little concern was shown for the lowest payoffs suggesting that maximin preferences are of little importance in strategic interactions. Further support for the difference aversion theory is given by Güth et al. (2003), who found that fairness concerns dominate efficiency concerns in dictator dilemma experiments where there is a trade-off between fairness and efficiency. ${ }^{1}$ The experiments by Güth and van Damme (1998) and Bolton et al. (1998), amongst others, are used by Bolton and Ockenfels (2008) to support the theory of self-centred fairness that is embodied in their model. These results were not supported by Charness and Rabin (2000, $2002),{ }^{2}$ who found that individuals did indeed care about the distributions of payoffs among other parties. Kagel and Wolfe (2001) designed a 3-person modification of the ultimatum game in order to test the Fehr-Schmidt and Bolton and Ockenfels models. ${ }^{3}$ Their results show insensitivity to third party allocations and reject both the difference aversion models; furthermore, their results even fail to support social-welfare preferences.

The lack of concurrence regarding the empirical evidence motivates further study into the nature of distributional concerns. This paper tests the relative performance of some of the more prominent social preference theories of difference aversion, maximin preferences

\footnotetext{
${ }^{1}$ In dictator dilemma games, the recipient receives more than the dictator donates.

${ }^{2}$ The authors designed an experiment with a direct test of Bolton and Ockenfels hypothesis that individuals are unconcerned about the allocation among other parties. The results reject the Bolton and Ockenfels model, but are consistent with both the social welfare and Fehr-Schmidt models.

${ }^{3}$ In this game, one person allocates a sum of money to two others, one of which is randomly chosen to accept or reject the offer. Rejection gives both the responder and the proposer zero income, but a positive consolation prize is given to the non-responder. The results show little reduction in rejection rates, holding offers constant, with and without consolation prizes, contrary to the prediction of both difference aversion models.
} 
and efficiency concerns in distributional experiments using an approach that is somewhat different to previous studies. Firstly, within the standard approach experiments are conducted using 2 or 3 players and it is therefore of interest to observe if there is any strong correspondence to any of the social preference models when there are more players involved. In addition, the parameters of the models are rarely estimated in previous studies, as the structures of these games do not usually provide sufficient information because they yield outcomes from choices that result in the highest utility for the individuals (dictator games, ultimatum games, binary choices between distributions etc.), rather than indifference between choices. Finally and most importantly, the results from previous experiments do not always allow us to discriminate between the different models as the results are often consistent with more than one model. In this paper the experiments are conducted in groups of 11 individuals, where each subject is required to state what we call their "equality equivalence" for an unequal distribution for the group. We define equality equivalence as the value of the egalitarian payoff for which the individual is indifferent between the unequal and the egalitarian outcome. ${ }^{4}$ As will be shown, the individuals' responses classify them into one of the different models, and the design of the experiment is such that membership in one of the models is mutually exclusive.

The rest of the paper is organized as follows. Section 2 provides a description of the experimental design and procedure, followed by an overview of the different social preference models in sections 3. The results from the study are presented in section 4 , followed by the conclusions in section 5 .

\footnotetext{
4 According to Rabin (1993), as well as Dufwenberg and Kirchsteiger (2004), intentions play a role when individuals are motivated by reciprocity considerations. If so, the individuals in this study, believing that the other respondents would base their choices out of "kindness" would wish to reciprocate this unselfish action. However, this study disregards such effects assuming that the individuals' responses reflect only their distributional concerns.
} 


\section{The Experiment}

\subsection{Experimental Design}

We design an experiment where individuals' preferences and the performance of the different models are evaluated by observing the equality equivalence (S) for three different distributions of money among the 11 subjects. The respondents were presented with three questions, for each of which there were two alternatives. Alternative 1 was a given (unequal) distribution for the group while Alternative 2 was the egalitarian distribution. The individual's task was to choose the level of money (S) in each case so that she is indifferent between the payoff distributions in Alternatives 1 and 2. . The value of $\mathrm{S}$ was required to be less than or equal to the respondents payoff in alternative 1. In all three questions, the total surplus in Alternative 1 is 1800 SEK while the individual's payoff is 300 SEK. ${ }^{5}$ The distributions in Alternative 1 differ in that the payoffs become more equal and in question 3 the lowest payoff increases from 0 to 150 SEK. Furthermore, the individuals own payoff is the highest in the group for the distributions in questions 2 and 3. The distributions of the three questions are presented in Figure 1 below. A translation of the exact presentation of the questions is given in the appendix.

Figure 1. Description of the distributions.

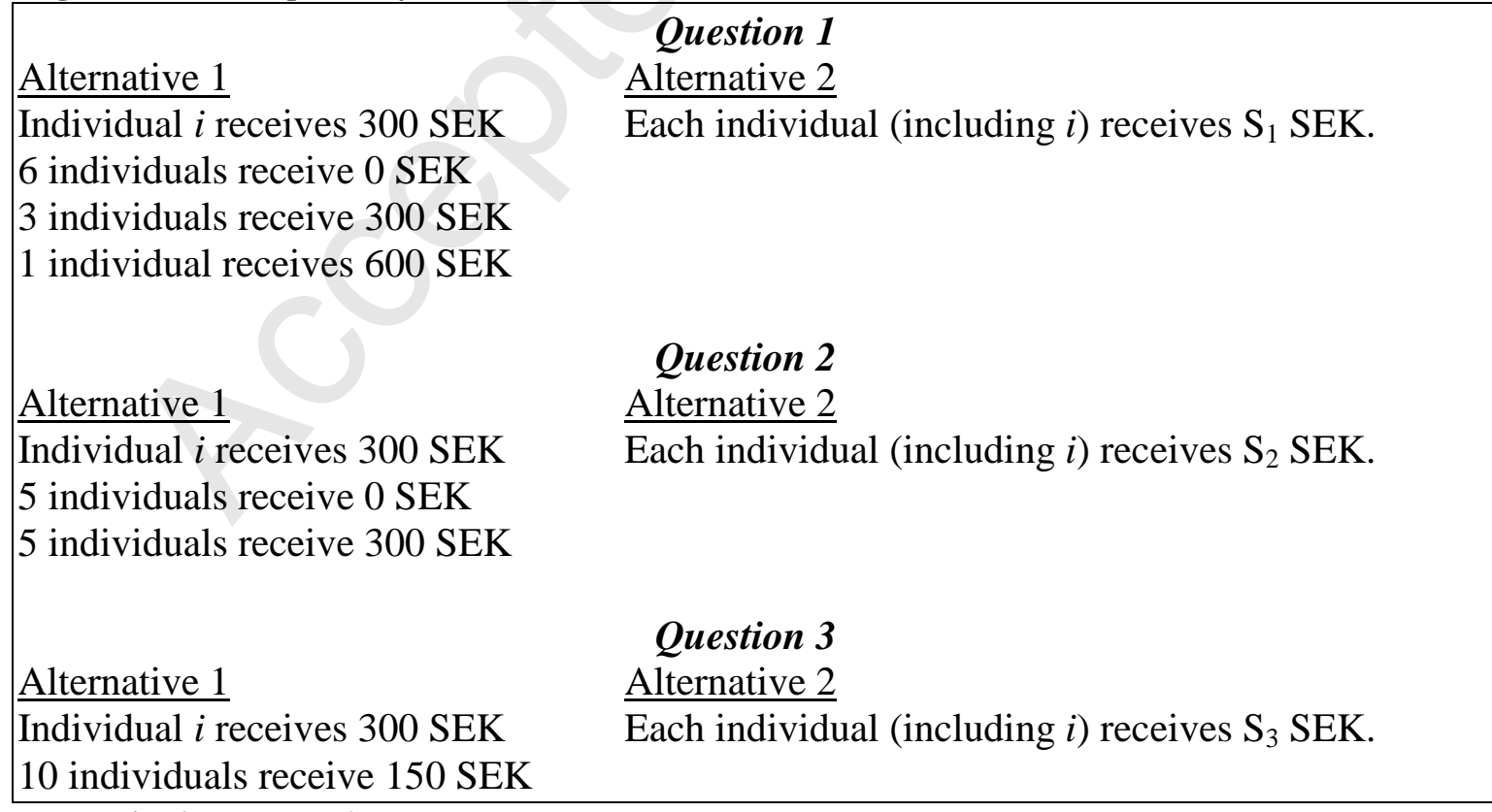

note: $i$ is the respondent

\footnotetext{
${ }^{5}$ At the time the experiment was conducted, 1 USD $=7.3$ SEK.
} 
A modification of the incentive mechanism by Becker et al. (1964) is used to avoid strategic responses by the participants. All participants receive the same payoff if the stated value for $\mathrm{S}$ is less than a random number subsequently drawn from a uniform distribution ranging between 0-300. This random number is also the payoff of each individual. In the case where $\mathrm{S}$ coincides with or exceeds the randomly drawn number, the payoffs are in accordance with Alternative 1. As respondents are restricted to stating values for $\mathrm{S}$ less than or equal to 300 which is their payoff in Alternative 1, stating one's equality equivalence is the dominant strategy. The individuals can then be categorised into the different models. The alternatives were designed so that membership is mutually exclusive in that it is not possible for a respondent to belong to more than one group.

While the behaviour of some participants appears to be consistent with the difference aversion models, it is possible that individuals may also have surplus concerns. Results from social preference research, for example, Andreoni and Miller (2002) and Charness and Rabin (2002) indicate that individuals take into account the impact of their actions on the total surplus (efficiency) and are thereby willing to make small sacrifices in order to increase the overall surplus. The difference aversion models do not incorporate efficiency concerns and in order to see whether such concerns are present, a follow up question was put to the participants. The question has similarities to the one sided dictator dilemma treatment used in the paper by Güth et al. (2003). The original distribution is equal for all players so that each individual receives 100 SEK. Individual $i$ has the possibility to donate money to the others in the group. For every SEK donated, the payoff of every other individual is increased by 0.25 SEK. Thus every SEK given away by individual $i$ will increase the total surplus by $1.5 \mathrm{SEK}$. If the values of $\mathrm{S}$ given by individual $i$ appear to correspond to the one of the difference aversion models above but a positive donation is made to increase the surplus then this is sufficient for us to conclude that in at least those cases the models are incomplete and concern for efficiency should be accounted for. 


\subsection{Experimental procedure}

A total of 132 students from various disciplines were recruited on campus at Karlstad University to participate in the main study with real payoffs. A follow up survey consisting of two hypothetical classroom experiments were performed on 221 subjects in order to test for any ordering and suggestive language effects that may have affected the results in the main study. ${ }^{6}$

Of the 132 subjects in the main study with real payoffs, 71 were male and 61 female. In total, 72 of the participants were students of economics who had completed at least one term of economics while the remaining 60 were students of law, technology, teaching and nursing. Subjects were recruited via classroom announcements where they could leave their telephone numbers on a list that was passed around the class if they wished to participate. These students were later contacted via telephone and invited to take part in a specific experimental session. The experiment was conducted in 12 sessions in groups of 11 students, although in order to ensure a full head count, 12 students were summoned on each occasion. Only the first 11 arrivals were accepted as participants while the $12^{\text {th }}$ was paid a show-up fee of $50 \mathrm{SEK}$.

The participants were seated individually with unobstructed views of all other participants. Each participant was given an envelope containing full instructions (a translation is available from the author upon request) as well as an identity number. The same identity number was printed on the back of the questionnaire. The session began with the experimenter explaining how the payment procedure guaranteed complete anonymity for the participants after which the distribution part of the survey was explained first along with the incentive mechanism. This part of the experiment took between 20-25 minutes. The distribution task was explained using an example with a distribution similar to those in the survey. The incentive mechanism was illustrated using trial runs assuming different varying S-values. The cognitive demand on the students is considerable in this kind of experiment, so great pains were taken to ensure that the students had understood the nature of the task as well as the incentive mechanism. ${ }^{7}$ The

\footnotetext{
${ }^{6} \mathrm{I}$ am indebted to the editor and an anonymous referee for proposing this test.

${ }^{7}$ Nonetheless, it is possible that some participants still did not grasp that stating their equality equivalence $\mathrm{S}$ is the dominant strategy. Thus they were also told that if they did not fully understand the incentive mechanism, they should "trust" the instructor in that it was in their best interest to answer in accordance
} 
three distributions were presented on the overhead and their characteristics were described to the subjects in a similar fashion as described in section 3. In order to assist the subjects in the distribution questions they were told the following:

"If you have difficulty in answering the questions you may wish to follow the following procedure:

Set $S$ in Alternative 2 to 300 SEK and ask yourself which alternative you would prefer. If you like both alternatives equally then set $S=300$. However, if you prefer Alternative 2 then lower the value of $S$ slightly and ask yourself the same question again. Repeat the procedure, decreasing or increasing the value of $S$ until you reach a point where you consider the two alternatives to be equal in value."

The participants were given time to answer the distribution questions before the donation to the surplus task was presented. Even in this case, examples of the effects of donations were given to ensure that the subjects fully understood the consequences. For example:

"If you choose to give away 10 SEK from your allocation then you will receive 90 SEK and each of the other 10 students will receive 102.50 SEK."

The donation numbers used in the examples were 0,10 and 100.

The subjects were asked to place their pens on their tables to signal when they had finished each task. Finally the participants were required to fill in some information regarding their socioeconomic status. The variables collected were gender, number of siblings, political preferences and choice of discipline.

Each experimental session lasted about 40 minutes. The questionnaires were collected and one was picked at random. A dice was thrown by the instructor to establish for which of the four questions the payoff would occur. For questions 1-3 the incentive mechanism was evoked where a number " $R$ " was picked at random from a box. If $R \leq S$ then the payoffs were according to Alternative 1 whereas if $\mathrm{R}>\mathrm{S}$ then all the individuals received the same payoff R. In the former case, identity numbers were picked one by one at random with the associated payoffs increasing in magnitude as the numbers were picked.

with their preferences and that they had nothing to gain, but could possibly lose by not doing so. They were further told that the instructor would stay behind at the end of the session to explain the incentive mechanism more thoroughly if they did not wish to ask questions in front of the group. 
If question 4 was picked, then the payoffs were based on the subject's response in the chosen questionnaire.

The instructor noted the payoffs on a sheet of paper which was given to another person and the participants were able to collect their payoffs individually using their identity cards. The payoffs ranged from 0 to 280 SEK and a total of 18,300 SEK was distributed making the average payoff 139 SEK per respondent.

The hypothetical survey was a comparison of two treatments performed in two separate classroom sessions. The first (H1) with 123 students replicated the script and ordering of the main experiment, the second (H2), with 98 students, excluded the script and reversed the order of the distributions in questions 2 and 3. Further, the distributions in $\mathrm{H} 2$ were presented sequentially rather than side by side.

\section{The models}

The models tested in this study are the difference aversion models of Fehr and Schmidt (1999) and Bolton and Ockenfels (2000), the social welfare model of Charness and Rabin (2000) as well as a very general inequality aversion model. In this section we present a general overview of the different models. We begin by considering the two difference aversion models. Fehr and Schmidt assume a utility function of the following form for individual i

$U_{i}=w_{i}-\alpha_{i} \frac{1}{n-1} \sum_{i \neq j} \max \left\{w_{j}-w_{i}, 0\right\}-\beta_{i} \frac{1}{n-1} \sum_{i \neq j} \max \left\{w_{i}-w_{j}, 0\right\}$,

where $\alpha_{i} \geq \beta_{i}, \quad 0 \leq \beta_{i}<1$ and $w_{i}$ is the payoff of individual $i$. The structure of this model incorporates both envy and altruism. The disutility from inequality is greater when another individual has a larger payoff than vice-versa thus the assumption is that envy is stronger than altruism. The implication behind $\beta_{i}<1$ is that the disutility from receiving more than others is never so great that the individual is willing to sacrifice money without benefiting others.

Bolton and Ockenfels present in the theory of Equity, reciprocity and competition (ERC) an unspecified motivation function that is given by $V_{i}=\left(w_{i}, s_{i}\right)$, 
where $w_{i}$ denotes own payoff and $s_{i}$ the individuals share of the total payoff. It is assumed that that the function increases in own payoff $w_{i}$, decreases as the relative payoff $s_{i}$ moves away from the social reference share $1 / n$. Thus for a given $w_{i}$, the function $V_{i}$ is maximised when $s_{i}=1 / n, n$ being the number of individuals in the reference group. In the case where $s_{i}>1 / n$ the marginal rate of substitution between absolute and relative payoffs will determine how much the individual is willing to sacrifice in order to obtain an egalitarian solution.

The difference between the two difference aversion models is that in the Fehr-Schmidt model the individual compares her own payoff with each and every other individual in the reference group. In the Bolton-Ockenfels model the individual's only concern is her share of the total surplus and the payoffs of other individuals do not enter directly into the motivation function. In the case where a transfer of money is made from an individual with a higher payoff to an individual with a lower payoff, utility will increase in the first model but remain unchanged in the second.

The social welfare model that we will test is the Quasi-maximin model of Charness and Rabin (2000), which is basically a reinterpretation of the Andreoni and Miller (2002) model $^{8}$ where people make sacrifices to increase the payoff of all recipients, but especially for the lowest payoff recipient. The individual's utility function is given by

$$
\mathrm{U}_{\mathrm{i}}=(1-\gamma) w_{i}+\gamma\left[\delta \min \left\{w_{1}, w_{2} \ldots w_{n}\right\}+(1-\delta) \sum_{j=1}^{n} w_{j}\right]
$$

where the parameter $\gamma \in[0,1]$ corresponds to the weight the individual places on social welfare, expressed as $\left[\delta \min \left\{w_{1}, w_{2} \ldots w_{n}\right\}+(1-\delta) \sum_{j=1}^{n} w_{j}\right]$, versus her own monetary payoff $w_{i}$. When $\gamma=0$ then preferences are consistent with pure self-interest. If $\gamma=1$, the individual displays purely "disinterested" preferences where the individual values the

\footnotetext{
${ }^{8}$ Charness and Rabin refer to the working paper by Andreoni and Miller from 1998 that was subsequently published in 2002 .
} 
payoffs of others as much as her own. The parameter $\delta \in[0,1]$ measures the degree of concern for helping the lowest payoff recipient versus increasing the total surplus. Thus $\delta=1$ is consistent with the Rawlsian criterion while $\delta=0$ corresponds to maximisation of the total surplus.

We also introduce a very general model where utility is assumed to be a function of some measure of inequality. With multi-person experiments, it is possible that the level of inequality per se is an issue. For example, in the Carlsson et al. (2005) study individuals were found to have strong preferences regarding the level of inequality per se in the case of income. In order to encompass this we introduce a general function assuming that the individual's utility is dependent on her own payoff $w_{i}$, the general level of inequality $\phi$ and some function $v\left(w_{1}, \ldots, w_{n}\right)$ of the payoffs of others so that the utility function is $\mathrm{U}_{\mathrm{i}}=U\left[w_{i}, \phi, v\left(w_{1}, \ldots, w_{n}\right)\right]$.

The function $v\left(w_{1}, \ldots, w_{n}\right)$ may for example represent concerns for the least payoff individual, concerns for the total surplus, differences between the individual's own payoff and the payoff of others or any combination of the above. We refrain from stipulating any precise functional form as the purpose here is merely to obtain some measure of the proportion of subjects that have concerns for inequality per se.

Depending on the values of the stated equality equivalence (S) each individual can be categorised into one of the different models. Defining the inequality premium, E, for a particular distribution as the maximum amount of money an individual is willing to sacrifice from her endowment in order to achieve an equal distribution for the group so that $\mathrm{E}_{\mathrm{i}}=300-\mathrm{S}_{\mathrm{i}}$, where $\mathrm{i}$ indicates the number of the question, we then have the following classification of responses.

1) If $\mathrm{E}_{2}=\mathrm{E}_{3}<\mathrm{E}_{1}$ then the individual's preferences fit the Fehr-Schmidt model. The distributions in questions 2 and 3 are equivalent in this case as the redistribution of payoffs between the other participants does not affect the average distances to the individuals own payoff. It is also necessary that the inequality premium in question 1 be higher than in the other two questions as the average distance from those with lower and 
higher payoffs increases, and thus the distribution in question 1 will give the individual the lowest utility.

2) If $\mathrm{E}_{1}=\mathrm{E}_{2}=\mathrm{E}_{3}>0$ then the individual's preferences correspond to Bolton and Ockenfels model. The ERC model assumes that individuals care only about their payoffs relative to the total and are unconcerned regarding the relative payoffs between the other participants. The individual's share of the total surplus is the same, and thus the inequality premiums will be the same in all 3 cases.

3) If $\mathrm{E}_{1}=\mathrm{E}_{2}>\mathrm{E}_{3}$ then the individual exhibits quasi-maximin preferences. Since the lowest payoff is the same in the first two questions and increases in the third, the inequality premium will decrease in the third question.

4) If $E_{1}>E_{2}>E_{3}$, then this implies that the preferences are consistent with the more general case where the individual has an aversion for inequality per se. Thus the premium that an inequality-averse individual is willing to pay will be decreasing as the degree of equality in the distributions increases.

5) If $\mathrm{E}_{1}=\mathrm{E}_{2}=\mathrm{E}_{3}=0$, then preferences correspond to pure self interest where the individual disregards the payoff of others. This is consistent with traditional microeconomic theory. 


\section{Results}

The values for the inequality premiums for the first two questions $\left(E_{1}\right.$ and $\left.E_{2}\right)$ range from 0 to 300 with means of 101 and 92 respectively. The corresponding values for $\mathrm{E}_{3}$ are from 0 to 200 with a mean of 57. Detailed tables including the means and standard deviations of the inequality premiums for the total and each group separately are given in table 1 below.

Table 1: Descriptives of the Equality premiums for all categories.

\begin{tabular}{|c|c|c|c|c|c|}
\hline & & Mean & $\begin{array}{c}\text { Std. } \\
\text { deviation }\end{array}$ & Minimum & Maximum \\
\hline \multirow{3}{*}{$\begin{array}{l}\text { Total } \\
\text { (132 respondents) }\end{array}$} & E1 & 100.98 & 59.570 & 0 & 300 \\
\hline & $\mathrm{E} 2$ & 91.88 & 54.324 & 0 & 300 \\
\hline & E3 & 56.86 & 48.659 & 0 & 200 \\
\hline \multirow{3}{*}{$\begin{array}{l}\text { Fehr-Schmidt } \\
(9 \text { respondents })\end{array}$} & E1 & 90.56 & 41.416 & 20 & 140 \\
\hline & E2 & 51.67 & 44.159 & 0 & 100 \\
\hline & E3 & 51.67 & 44.159 & 0 & 100 \\
\hline \multirow{3}{*}{$\begin{array}{l}\text { ERC } \\
(28 \text { respondents) }\end{array}$} & E1 & 91.79 & 37.348 & 20 & 150 \\
\hline & E2 & 91.79 & 37.348 & 20 & 150 \\
\hline & E3 & 91.79 & 37.348 & 20 & 150 \\
\hline \multirow{3}{*}{$\begin{array}{l}\text { Quasi maximin } \\
\text { (36 respondents) }\end{array}$} & E1 & 113.06 & 51.036 & 30 & 300 \\
\hline & E2 & 113.06 & 51.036 & 30 & 300 \\
\hline & E3 & 53.33 & 45.529 & 0 & 150 \\
\hline \multirow{3}{*}{$\begin{array}{l}\text { Inequality } \\
\text { aversion } \\
\text { (39 respondents) }\end{array}$} & E1 & 136.02 & 58.739 & 20 & 250 \\
\hline & E2 & 100.21 & 52.541 & 10 & 220 \\
\hline & E3 & 52.05 & 49.227 & 0 & 200 \\
\hline \multirow{3}{*}{$\begin{array}{l}\text { Self interest } \\
(10 \text { respondents })\end{array}$} & E1 & 0 & 0 & 0 & 0 \\
\hline & E2 & 0 & 0 & 0 & 0 \\
\hline & E3 & 0 & 0 & 0 & 0 \\
\hline \multirow{3}{*}{$\begin{array}{l}\text { Others } \\
\text { (10 respondents) }\end{array}$} & E1 & 57 & 38.601 & 0 & 120 \\
\hline & E2 & 111.50 & 41.637 & 10 & 150 \\
\hline & E3 & 52 & 51.597 & 0 & 120 \\
\hline
\end{tabular}

If we look at the mean values directly, we have that $E_{1}>E_{2}>E_{3}$. This implies that preferences are consistent with the inequality aversion model that was developed in this paper. However, individuals are heterogeneous between as well as within models and we use the inequality premiums of each individual to classify them into the different models.

Table 2 below presents the number of participants whose responses are consistent with the different models; note again that the groups are mutually exclusive. The group 
"Other" consists of individuals whose preferences do not appear to fit any of the models above. The table also includes the number of individuals in each category that sacrificed money in order to increase the total surplus in the follow-up question.

Table 2: Frequency of participants that qualify into the different model categories and give surplus increasing donations.

\begin{tabular}{|c|c|c|}
\hline & $\begin{array}{l}\text { Number of respondents } \\
\text { within each category. } \\
\text { (\% of total) }\end{array}$ & $\begin{array}{l}\text { Number of respondents } \\
\text { that gave surplus } \\
\text { increasing donations. } \\
\text { (\% of group) }\end{array}$ \\
\hline Fehr-Schmidt & $9(6.8 \%)$ & $3(33.3 \%)$ \\
\hline ERC & $28(21.1 \%)$ & $9 \quad(32.1 \%)$ \\
\hline Quasi-Maximin & $36(27.3 \%)$ & $10 \quad(27.8 \%)$ \\
\hline Inequality-averse & $39(29.5 \%)$ & $11 \quad(28.2 \%)$ \\
\hline Self Interest & $10(7.6 \%)$ & $\begin{array}{ll}0 & (0.00 \%)\end{array}$ \\
\hline Other & $10(7.6 \%)$ & $3 \quad(30.0 \%)$ \\
\hline Total & $132(100 \%)$ & $36 \quad(27.3 \%)$ \\
\hline
\end{tabular}

There is little difference in the number of respondents that fall into the three different categories. The group of responses consistent with the general category of inequality aversion was the largest with 39 individuals (29.5\%), followed by the difference aversion group consisting of the Fehr-Schmidt and the ERC models with a total of 37 individuals (28\%). Within the difference aversion group the ERC model fares considerably better than the Fehr-Schmidt model with more than three times the number of participants falling into the former category. The Quasi-maximin model was in close third place with 36 individuals $(27.3 \%)$. Although the difference aversion models appear to perform at least as well as the Quasi-maximin model, each group receiving roughly $28 \%$ of the respondents, nearly a third of the respondents in the difference aversion group made donations in order to increase the surplus, thereby also increasing the level of inequality. This is in direct conflict with the predictions of both difference aversion models and the implication would be that for those individuals at least, the models do not completely capture preferences. Nor can we exclude possible preferences for efficiency among those individuals within the group who did not make a donation as the disutility from the lower 
payoff and increased inequality may not have compensated for the utility derived from the increase in the total surplus. There were 10 individuals $(7.5 \%)$ in the "Self interest" group, i.e. those individuals who were unconcerned with the payoff of others. ${ }^{9}$ The group "Others" had the same number of individuals as the Self Interest group. We are unable to make any claims concerning the preferences of this group. It is likely that some or all of these respondents did not understand the task and were confused in their responses. The only general pattern observed was that 9 out of the 10 of the respondents considered the distribution in question 2 to be the worst and as such had the highest inequality premiums.

One possible problem is that the order and presentation of the distributions and the attached script on the differences between the same may have created an ordering bias in favour of the inequality aversion model. In order to test for such a bias, two hypothetical classroom surveys (H1 and H2) were performed. H1 replicated the script and ordering of the main experiment. In the second, H2, the distributions were presented sequentially, further, the subjects were given no script in $\mathrm{H} 2$ and the order of the distributions in questions 2 and 3 were reversed. The frequency results from the hypothetical studies are given in Table 3 below.

Table 3: Number of respondents within each category in the hypothetical studies $H 1$ and H2 used to check for ordering effects. (\% of total)

\begin{tabular}{|l|c|c|}
\hline & H1 & H2 \\
\hline Fehr-Schmidt & $12(10.5 \%)$ & $6 \quad(6.1 \%)$ \\
\hline ERC & $20(17.5 \%)$ & $13(13.3 \%)$ \\
\hline Quasi-Maximi & $27(23.7 \%)$ & $16(16.3 \%)$ \\
\hline Inequality-averse & $29(25.4 \%)$ & $22(22.4 \%)$ \\
\hline Self Interest & $20(17.5 \%)$ & $18(18.4 \%)$ \\
\hline Other & $15(13.2 \%)$ & $23(23.5 \%)$ \\
\hline Total & $\mathbf{1 2 3}$ & $\mathbf{9 8}$ \\
\hline
\end{tabular}

A Chi-2 test shows no significant difference $\left(\chi^{2}(5)=6.3, \mathrm{p}=0.28\right)$ between the two hypothetical treatments. Further, using a two-sample test about proportion, the results from the main study were compared with those from the $\mathrm{H} 2$ study to test for a bias

\footnotetext{
${ }^{9}$ This is considerably less than in previous studies where $30 \%$ is the proportion mentioned in some of the literature but consistent with results from experiments where reciprocity is not an issue, e.g. Charness and Rabin (2000) where the proportion of individuals motivated solely by self-interest is around $10 \%$.
} 
toward inequality aversion against the other three categories. None was found $(\mathrm{Z}=-0.48$, $\mathrm{p}=0.31)$.

We now return to the results of the main study. Apart from stating their inequality premium for the three distributions, the participants were also required to answer some questions on their socio-economic status. A multinomial logit model was used in order to see if it was possible to classify respondents into the different model groups based on values of the set of socio-economic characteristics. The only variable found to have any effect was gender in the model group "Self Interest" where $80 \%$ of the individuals in the group were male. ${ }^{10}$ Consequently, we are not able to explain the difference in preferences using observable individual characteristics to any great extent.

As mentioned in the introduction it is possible to estimate the parameters values of the Fehr-Schmidt as well as the Charness-Rabin utility functions using the information provided in the experiment. The parameter values of both models were calculated and the descriptive statistics of these are given in tables 4 and $5 .^{11}$

Table 4: Estimations of the parameter values for the Fehr-Schmidt category.

\begin{tabular}{|c|c|c|c|c|}
\hline & Mean & Std. Deviation & Minimum & Maximum \\
\hline $\boldsymbol{\alpha}$ & 0.9519 & 1.03858 & 0.13 & 3.33 \\
\hline $\boldsymbol{\beta}$ & 0.3444 & 0.29439 & 0.00 & 0.67 \\
\hline
\end{tabular}

The Pearson correlation measure between the two parameters $\alpha$ and $\beta$ for the Fehr Schmidt group was found to be -0.625 at a significance level of 0.36 . Thus, individuals with higher $\beta$ values tend to have lower $\alpha$ values and vice versa, or in other words, those who are more altruistic tend to be less envious and vice versa. In the Quasi-maximin group it was found that as many as 11 of the $\delta$ parameter values and one of the $\gamma$ parameter values were greater than 1 which is clearly unreasonable as $\delta>1$ implies that the parameter for efficiency $(1-\delta)$ is less than 0 implying that an increase in efficiency

\footnotetext{
${ }^{10}$ This corresponds with results from previous studies for example Selten and Ockenfels (1998, pg 529). However as there are only 10 respondents in the Self Interest group it is not possible to draw any definite conclusions from this result.

${ }^{11}$ Bolton and Ockenfels do not use a specific function to describe preferences. Similarly, we do not specify a precise functional form for the Bolton and Ockenfels nor the comparison inequality aversion model. In both cases the value of the inequality premium is used as the measure of difference aversion and inequality aversion respectively.
} 
lowers the individual's utility. With the numbers in this particular experiment it is sufficient that $\mathrm{E}_{2}>2 \mathrm{E}_{3}$ for $\delta$ to be greater than 1. The descriptive statistics in table 5 below also include adjusted parameters where values greater than 1 were set equal to 1 .

Table 5: Estimations of the parameter values for Quasi-maximin category.

\begin{tabular}{|l|c|c|c|c|}
\hline & Mean & Std. Deviation & Minimum & Maximum \\
\hline $\boldsymbol{\gamma}$ _adjusted & 0.3970 & 0.19847 & 0.08 & 1.00 \\
\hline $\boldsymbol{\delta}$ _adjusted & 0.9267 & 0.13605 & 0.48 & 1.00 \\
\hline unadjusted $\boldsymbol{\gamma}$ values & 0.3984 & 0.20294 & 0.08 & 1.05 \\
\hline unadjusted $\boldsymbol{\delta}$ values & 0.9571 & 0.15922 & 0.48 & 1.11 \\
\hline
\end{tabular}

More than $60 \%$ of the adjusted parameter values for efficiency (1- $\delta)$ were zero implying that efficiency was not a factor considered important by most of the respondents. Two of the respondents had adjusted values of $\gamma=1$ implying that they have purely "disinterested" preferences in that they value the payoffs of others as much as their own. ${ }^{12}$

The test for efficiency in the follow-up question is rigorous in the sense that those individuals who make positive donations to the common surplus are both sacrificing money and moving away from the egalitarian solution, and as such their concern for efficiency is irrefutable. However, although the test above is sufficient in order to ascertain preferences for efficiency, we cannot rule out such preferences for those who do not make such a donation as it is quite possible that the utility gain from the increased surplus does not outweigh the disutility from the decrease in own wealth and equality. Positive donations were made by 36 (27.3\%) individuals. Of these, the donations ranged between 5 and 100 SEK, with a mean and standard deviation of 28 and 22 respectively. These results are in stark contrast to the results from the two-person dictator dilemma game by Güth, Kliemt and Ockenfels (2003) who found that individuals never violate the fairness constraint in order to increase efficiency. If we consider efficiency in the Quasimaximin model, we found 15 individuals (42\%) exhibited preferences for efficiency within the model. ${ }^{13}$ Allowing for inaccuracies in model specifications we thus have at least 41 individuals $(31 \%)$ in this study who appear to exhibit strong preferences for

\footnotetext{
${ }^{12}$ One of the two respondents had parameter values $\delta=\gamma=1$ which corresponds to the extreme case where the individual's only concern is for the lowest payoff recipient.

${ }^{13}$ There were 15 respondents within the Quasi-maximin model who either had a positive parameter for efficiency (14), gave a surplus increasing donation (10) or both.
} 
efficiency. Furthermore, we find the proportion of respondents making positive donations, and as such have strong preferences regarding efficiency to be stable between the groups (with the exception of the Self-Interest group who as expected exhibited no efficiency concerns) which would lead us to believe that preferences for efficiency are not overrepresented within the Quasi-maximin group. If we accept this notion then the estimate of subjects with efficiency concerns within this study would then be 51 or roughly $38.5 \%$. These results support the conclusions of Engelmann and Strobel that distribution concerns are a significant factor in pure distributional situations, ${ }^{14}$ Fehr et al. (2006) argue that the relevance of the efficiency motive is largely restricted to students of economics and business administration who value efficiency rather than equality. It might be the case that students of economics may have been taught that efficiency should be considered as an important issue and as such would value equity less and efficiency more than students of other disciplines so we checked for subject pool effects in this issue. Of the 132 participants, 20 of 72 economists $(27.8 \%)$ and 16 of 60 non-economists $(26.7 \%)$ gave surplus increasing donations. We tested using a Chi-2 test whether it is more likely that economists gave positive donations than non-economists. Similarly, we also checked for any relationship between choice of discipline and surplus concerns. In addition, we conducted t-tests to check if the mean donations differed between the two groups in that economists contributed more toward increasing the total surplus than others. The results show no significant difference between economists and non-economists in any of the tests conducted. Thus, our results do not support the argument made by Fehr and Schmidt that efficiency concerns are mainly restricted to students of economics and business.

\section{Conclusions}

This paper uses a distributional experiment in order to test the performance of some of the better known social preference theories and efficiency concerns in a neutral arena in order to examine how people respond to unfair outcomes in a multi-person setting. The experimental design is somewhat different to previous work in this field. The main difference is that the subjects' responses classify their preferences into only one of the

\footnotetext{
${ }^{14}$ Fehr and Schmidt also argue that the relevance of the efficiency motive is largely restricted to nonstrategic interactions.
} 
different categories, while results from previous experiments are often consistent with more than one model. The results show that the individuals in this study are heterogeneous, and that they do not follow any single notion of fairness or inequality aversion. While the number of subjects that qualified into the three categories was fairly even, we found that within the difference aversion group, the ERC model performed considerably better than the Fehr-Schmidt model with more than three times the number of participants falling into the former category. Although the difference aversion category appears to perform at least as well as the other two, contrary to the model specification nearly a third of the respondents in the group made donations in order to increase the surplus. While difference aversion models may provide an insight into players' willingness to donate to others when ahead, they cannot explain donations which lead to an increased level of inequality. This suggests that in at least a third of the cases the difference aversion models do not completely capture preferences. Finally, we found that roughly one third of the respondents have quite strong concerns for the total surplus. It is sometimes argued that the relevance of the efficiency motive is largely restricted to students of economics and business administration and is of less concern to students of other disciplines. This study found no such correlation. 


\section{References}

Andreoni, J., Miller, J., 2002. Giving according to GARP: An experimental test of the consistency of preferences for altruism, Econometrica 70, 737 - 54.

Becker, G.M., DeGroot, M. H., Marschak, J., 1964. Measuring utility by a singleresponse sequential method. Behavioral Science 9, 226-32.

Bolton, G. E., Katok, E., Zwick, R., 1998. Dictator game giving: Rules of fairness versus acts of kindness. International Journal of Game Theory 27, 269-299.

Bolton, G. E., Ockenfels, A., 2000. ERC: A theory of equity, reciprocity and competition. American Economic Review 901, 166-93.

Bolton, G. E,. Ockenfels, A., 2008. Self-centered fairness in games with more than two players. In: Plott, C.R., Smith, V. (Eds.). Handbook of Experimental Economics Results 1, 4, 531-540.

Carlsson, F., Daruvala, D., Johansson-Stenman, O., 2005. Are people inequalityaverse, or just risk-averse? Economica 72, 287 375-396.

Charness, G., Rabin, M. 2000., Social preferences: some simple tests and a new model. Working paper, University of California.

Charness, G., Rabin, M., 2002. Understanding social preferences with simple tests. Quarterly Journal of Economics 117 3,.817-69.

Charness, G., Grosskopf, B., 2001. Happiness and relative payoffs-An experimental study. Journal of Economic Behavior and Organization 45, 3 301-28.

Dufwenberg, M., Kirchsteiger, G., 2004. A theory of sequential reciprocity. Games and Economic Behavior 47, 268-298.

Engelmann, D., Strobel, M., 2004. Inequality aversion, efficiency, and maximin preferences in simple distribution experiments. American Economic Review 94, 4 85769.

Fehr, E and Schmidt, K. M., 1999. A theory of fairness, competition and cooperation. Quarterly Journal of Economics 114, 817-68.

Fehr, E., Schmidt, K. M., Naef, M., 2006. Inequality aversion, efficiency and maximin preferences in simple distribution experiments: Comment. American Economic Review 96, 5 1912-1917.

Fehr, E., Schmidt, K. M., 2003. Theories of fairness and reciprocity - evidence and economic applications. In: Dewatripont, M., Hansen, L., Turnovsky, S. (Eds.). Advances 
in Economics and Econometrics $-8^{\text {th }}$ World Congress, Econometric Society Monographs, Cambridge, Cambridge University.

Frechette, G. R., Kagel, J.H., Lehrer S.F., 2003. Bargaining in legislatures: An experimental investigation of open versus closed amendment rules. American Political Science Review 97, 221-32.

Güth, W and Van Damme, E., 1998. Information, strategic behavior and fairness in ultimatum bargaining: an experimental study. Journal of Mathematical Psychology 42, 227-47.

Güth, W., Kliemt, H., Ockenfels, A., 2003. Fairness versus efficiency: An experimental study of mutual gift giving. Journal of Economic Behavior and Organization 50, 465-75.

Kagel, J.H., Wolfe, K., 2001. Tests of fairness models based on equity considerations in a three-person ultimatum game. Experimental Economics 4, 203-20.

Kritikos, A., Bolle, F., 2001. Distributional concerns: Equity or efficiency-oriented? Economics Letters 73, 3 333-38.

Loewenstein, G., Bazerman, M., Thompson, L., 1989. Social Utility and decision making in interpersonal contexts. Journal of Personality and Social Psychology LVII, 426-41.

Rabin, M., 1993. Incorporating fairness into game theory and economics. American Economic Review 83, 1281-1302.

Selten, R., Ockenfels, A., 1998. An experimental solidarity game. Journal of Economic Behavior and Organization 34, 517-39. 
Appendix - Translation of the exact presentation of the questions in the questionnaire.

\section{Questions 1-3.}

You have just been shown an example of your task by the monitor. You will now be required to answer three questions that are similar to the example.

For Alternative 1, the total allocation of money is 1800 SEK for all three questions and your share is always $300 \mathrm{SEK}$.

The questions differ in that the allocation between the participants becomes more even. The distribution in question 2 is more even than in question 1 and question 3 in turn, is more even than in question 2. In addition the lowest payoff increases to $150 \mathrm{SEK}$ in question 3.

The distributions for Alternative 1 for the three questions are presented below.

\section{$\underline{\text { Alternative } 1}$}

Question 1

Question 2

Question 3

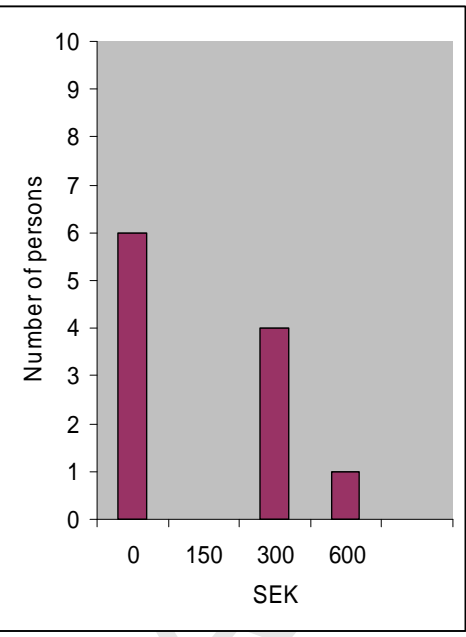

You receive 300 SEK 6 people receive $0 \mathrm{SEK}$ SEK

3 people receive 300 SEK 1 person receives $600 \mathrm{SEK}$

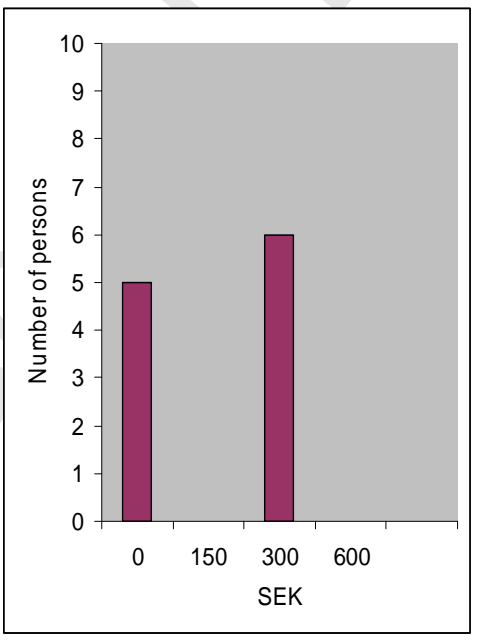

You receive 300 SEK 5 people receive 0 SEK

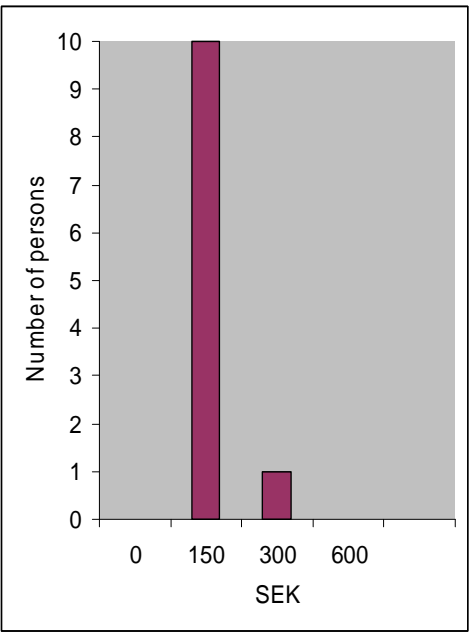

You receive 300 SEK

10 people receive 150

5 people receive $300 \mathrm{SEK}$

\section{$\underline{\text { Alternative } 2}$}

All participants (including you) receive the same amount_S_SEK. 
Answer 1

I like the distribution in Alternative 1 in question 1 as much as the distribution in Alternative 2 when $S=$ SEK.

Answer 2

I like the distribution in Alternative 1 in question 2 as much as the distribution in Alternative 2 when $\mathrm{S}=$ SEK.

Answer 3

I like the distribution in Alternative 1 in question 3 as much as the distribution in Alternative 2 when $\mathrm{S}=$ SEK.

\section{Question 4.}

In this question you have the possibility to give away money, if you so wish, from your allocation to the others in the group. For every SEK you choose to give away, each of the other participants will receive 0.25 SEK more.

Each person in the group receives 100 SEK.

Answer 4

I wish to give away SEK from my 100 SEK to the others in the group. 